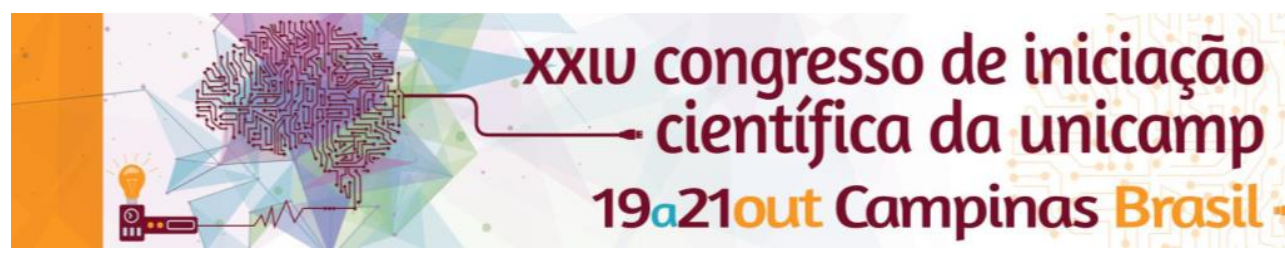

\title{
Transferência de Contaminantes na Cadeia Alimentar, Simulação e Modelagem Matemática
}

\author{
Thaís S. Rossi, Elaine C. C. Poletti
}

\section{Resumo}

A emissão de contaminantes em sistemas aquáticos têm crescido de forma rápida como consequência de atividades industriais (lançamento de efluentes em rios, mares e oceanos), urbanas, até mesmo como consequência das atividades naturais que são aceleradas graças às influências antrópicas. Essas emissões afetam de maneira negativa os ecossistemas aquáticos, pois podem causar a extinção de algumas espécies, e interferir em cadeias alimentares, acarretando em prejuízos para os níveis tróficos. A presente pesquisa de iniciação científica abordou, via modelagem matemática, a transferência de contaminantes ao longo cadeia alimentar, com três níveis tróficos, em sistemas aquáticos. Baseados num sistema de equações diferenciais, o estudo focou a resolução matemática do sistema, bem como simulações computacionais que possibilitaram entendimentos sobre o processo de contaminação e de transferência de contaminantes entre os diversos níveis tróficos.

\section{Palavras-chave: Impacto Ambiental; Transferência de Contaminantes em Cadeia Alimentar; Corpos Hídricos.}

\section{Introdução}

A preocupação com a poluição e com os impactos ambientais aumentou nos últimos anos pois estão cada vez mais presentes no ecossistema. A presença de contaminantes no meio ambiente se deve, principalmente, às atividades antrópicas e sua proporção ligada ao desenvolvimento industrial e agrícola que fazem uso indiscriminado de produtos químicos e substâncias potencialmente tóxicas que seguem para os corpos hídricos e para o solo causando modificações e impacto ambiental.

Os efeitos tóxicos podem ser causados tanto em organismos isolados, quanto em cadeias alimentares [1]. Em sistemas de cadeias alimentares, todos os níveis tróficos podem sofrer os efeitos do contaminante.

Ao passar por cada nível trófico, os contaminantes podem causar modificações na dinâmica da população e na forma com que se reproduzem, além de influenciar outros fatores tais como migração, efeitos teratogênicos, taxa de mortalidade, etc.

Além disso, ao que diz respeito aos corpos hídricos, a transferência do contaminante em uma cadeia alimentar, pode chegar ao homem e afetar toda a biota aquática.

No presente trabalho,utiliza-se a modelagem matemática na análise da transferência de contaminantes em uma cadeia alimentar, considerando-se 3 níveis tróficos.

\section{Resultados e Discussão}

De acordo com [2], a transferência de contaminantes em um sistema de cadeia alimentar, com três níveis tróficos pode ser modelado através de:

$$
\begin{aligned}
& \frac{d m_{1}(t)}{d t}=-\lambda_{1} m_{1}(t)-k_{12} m_{1}(t) \\
& \frac{d m_{2}(t)}{d t}=-\lambda_{2} m_{2}(t)-k_{23} m_{2}(t)+k_{12} m_{1}(t) \\
& \frac{d m_{3}(t)}{d t}=+k_{23} m_{2}(t)-\lambda_{3} m_{1}(t)
\end{aligned}
$$

com $k_{i j}$ representando a transferência de contaminante do nível trófico $i$ para o nível trófico $j$ e $\lambda_{i}$ representa o coeficinte de eliminação do nível trófico $i$.

Neste sistema, no primeiro nível da cadeia alimentar uma parte do contaminante é metabolizada e eliminada pelo organismo e outra parte é segue para o próximo nível. Da mesma forma, o segundo nível trófico recebe uma parcela do nível trófico anterior e metaboliza e elimina uma parte, transferindo uma parcela para o próximo nível trófico. Finalmente o útimo nível trófico recebe uma parcela do nível trófico anterior e metaboliza e elimina uma parte do contaminante.

De modo a resolver o sistema de equações diferenciais, adotando-se as condições iniciais $m_{1}(0)=m_{0}$, $m_{2}(0)=m_{3}(0)=0$, a solução dada por:

$$
\begin{gathered}
m_{1}(t)=m_{0} e^{-\left(k_{12}+\lambda_{1}\right) t} \\
m_{2}(t)=\frac{m_{0} k_{12}\left(e^{-\left(k_{12}+\lambda_{1}\right) t}-e^{-\left(k_{23}+\lambda_{2}\right) t}\right)}{\left(-\lambda_{1}-k_{12}+\lambda_{2}+k_{23}\right)} \\
m_{3}(t)=m_{0} k_{12} k_{23}\left[\frac{e^{-\left(k_{12}+\lambda_{1}\right) t}}{\left(-\lambda_{1}-k_{12}+\lambda_{2}+k_{23}\right)\left(\lambda_{3}-\lambda_{1}-k_{12}\right)}+\right. \\
\left.\frac{e^{-\left(k_{23}+\lambda_{2}\right) t}}{\left(-\lambda_{1}-k_{12}+\lambda_{2}+k_{23}\right)\left(\lambda_{2}-\lambda_{3}+k_{23}\right)}+\frac{e^{-\lambda_{3} t}}{\left(-\lambda_{1}-k_{12}+\lambda 3\right)\left(\lambda_{3}-\lambda_{1}-k_{12}\right)}\right]
\end{gathered}
$$

\section{Conclusões}

O modelo estudado possibilita uma análise acerca do processo de transferência de contaminante num sistema de cadeia alimentar com três níveis tróficos. Discussões neste sentido subsidiam avaliações de concentrações de contaminantes em organismos e possibilitam entendimentos e tomadas de decisão.

\section{Agradecimentos}

Agradecemos a PRP, ao Programa Institucional de bolsas de Iniciação Científica e Tecnológica e ao CNPq.

\footnotetext{
${ }^{1}$ ZAGATTO,Pedro A. Ecotoxicologia. In: BERTOLETTI, Eduardo; ZAGATTO, Pedro A. Ecotoxicologia Aquática: Princípios e Aplicações. 2. ed. São Carlos: RiMa, 2008. p.1-2

[2] TRAPP, S. \& MATHIES, M. Chemodynamics and Environmental Modeling: An Introduction. Springer-Verlag Berlin.1998.
} 